Research, Society and Development, v. 10, n. 9, e21910917966, 2021

(CC BY 4.0) | ISSN 2525-3409 | DOI: http://dx.doi.org/10.33448/rsd-v10i9.17966

\title{
Efeito dos sistemas de manejo e do uso do solo na população de microrganismos do
}

\section{Solo}

Effect of management systems and land use on the population of soil microorganisms

Efecto de los sistemas de manejo y uso de la tierra sobre la población de microorganismos del suelo

Recebido: 06/07/2021 | Revisado: 11/07/2021 | Aceito: 15/07/2021 | Publicado: 25/07/2021

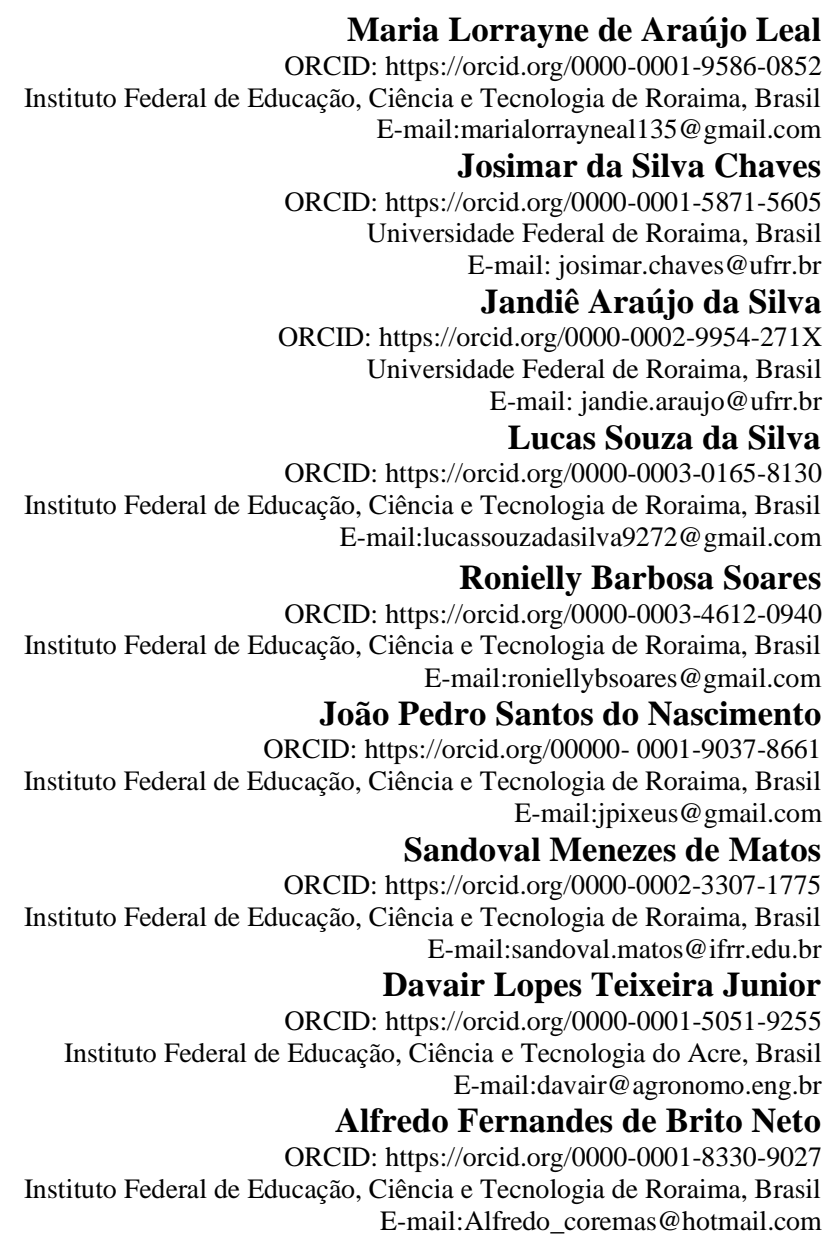

\section{Resumo}

As avaliações quantitativas da densidade populacional na comunidade microbiana nos solos são importantes para estabelecer relações ecológicas que ocorrem no solo e identificar fatores que exercem influência no equilíbrio microbiológico. Objetivou-se quantificar os microrganismos do solo com potencial de uso agrícola presente em diferentes manejos de uso do solo. O experimento foi conduzido no Instituto Federal de Ciências e Tecnologia de Roraima - Campus Novo Paraíso, no município de Caracaraí, Roraima. O experimento foi realizado em três áreas, solo em sistemas de cultivo consorciados, área com gliricídia, laranja e banana, área com laranja e essência florestal e mata. Em cada área foi coletado amostras de solo nas profundidades de 0-10 e 10-20 cm. A microbiota ativa do solo foi avaliada pela técnica de plaqueamento em superfície. A quantificação foi obtida por unidades formadoras de colônias por grama de solo (UFC g solo ${ }^{-1}$ ). As placas foram incubadas em estufa de crescimento a $28{ }^{\circ} \mathrm{C}$ por 48 e 96 horas, após esse período foi realizada a contagens das unidades formadoras de colônias. A quantificação dos organismos amonificadores, celulolíticos e actinobactérias foi obtido pela suspensão do solo, utilizando meios de cultura específicos para cada organismo. Os resultados demostram que o solo com o consórcio gliricídia, laranja e banana apresenta uma maior população de microrganismos (total, celulolíticos, amonificadores e actinobactérias), 
Research, Society and Development, v. 10, n. 9, e21910917966, 2021

(CC BY 4.0) | ISSN 2525-3409 | DOI: http://dx.doi.org/10.33448/rsd-v10i9.17966

mostrando ser uma alternativa para sistemas de consórcios com culturas agrícolas, proporcionando uma maior biodiversidade de microrganismos no solo, além de ajudar no fornecimento de nitrogênio para as espécies.

Palavras-chave: Gliricídia; População; Profundidade; Unidade formadora de colônia.

\begin{abstract}
Quantitative assessments of population density in the microbial community in soils are important to establish ecological relationships that occur in the soil and to identify factors that influence the microbiological balance. The objective was to quantify soil microorganisms with potential for agricultural use present in different land use management. The experiment was conducted at the Federal Institute of Science and Technology of Roraima Campus Novo Paraíso, in the municipality of Caracaraí, Roraima. The experiment was carried out in three areas, soil in intercropping systems, area with gliricidia, orange and banana, area with orange and forest essence and forest. In each area, soil samples were collected at depths of 0-10 and 10-20 cm. The active soil microbiota was evaluated by the surface plating technique. Quantification was obtained by colony forming units per gram of soil (CFU $\mathrm{g}$ soil ${ }^{-1}$ ). The plates were incubated in a growth oven at $28^{\circ} \mathrm{C}$ for 48 and 96 hours, after which the colony forming units were counted. The quantification of ammonifying, cellulolytic and actinobacteria organisms was obtained by suspending the soil, using specific culture media for each organism. The results show that the soil with the intercropping gliricidia, orange and banana has a greater population of microorganisms (total, cellulolytic, ammonifiers and actinobacteria), showing that it is an alternative for intercropping systems with agricultural crops, providing a greater biodiversity of microorganisms in the soil, in addition to helping in the supply of nitrogen for the species.
\end{abstract}

Keywords: Glyricide; Population; Depth; Colony forming unit.

\begin{abstract}
Resumen
Las evaluaciones cuantitativas de la densidad de población en la comunidad microbiana en los suelos son importantes para establecer las relaciones ecológicas que ocurren en el suelo y para identificar los factores que influyen en el equilibrio microbiológico. El objetivo fue cuantificar los microorganismos del suelo con potencial de uso agrícola presentes en diferentes ordenamientos territoriales. El experimento se realizó en el Instituto Federal de Ciencia y Tecnología de Roraima - Campus Novo Paraíso, en el municipio de Caracaraí, Roraima. El experimento se realizó en tres áreas, suelo en sistemas de cultivos intercalados, área con gliricidia, naranja y banano, área con esencia de naranja y bosque y bosque. En cada área, se recolectaron muestras de suelo a profundidades de 0-10 y 10-20 cm. La microbiota activa del suelo se evaluó mediante la técnica de recubrimiento superficial. La cuantificación se obtuvo por unidades formadoras de colonias por gramo de suelo (UFC g suelo ${ }^{-1}$ ). Las placas se incubaron en un horno de crecimiento a $28{ }^{\circ} \mathrm{C}$ durante 48 y 96 horas, luego de lo cual se contaron las unidades formadoras de colonias. La cuantificación de organismos amonificantes, celulolíticos y actinobacterias se obtuvo suspendiendo el suelo, utilizando medios de cultivo específicos para cada organismo. Los resultados muestran que el suelo con gliricidios intercalados, naranja y banano tiene una mayor población de microorganismos (totales, celulolíticos, amonificantes y actinobacterias), demostrando que es una alternativa para los sistemas de intercalación con cultivos agrícolas, proporcionando una mayor biodiversidad de microorganismos en el suelo, además de ayudar en el suministro de nitrógeno para la especie.
\end{abstract}

Palabras clave: Glyricide; Población; Profundidad; Unidad de formación de colonia.

\title{
1. Introdução
}

O solo é um recurso natural fundamental para a produção agrícola, e sua qualidade é formada por fatores químicos, físicos, biológicos e ecológicos, podendo ser modificados em prol de melhor qualidade. A qualidade do solo é uma propriedade de sustentabilidade das culturas, influenciando também na saúde das plantas, animais e consequentemente em seres humanos (Melo et al., 2017). O solo é um habitat naturalmente diversificado, com comunidades biológicas altamente complexas, nas quais se encontram diferentes formas de microrganismos, tanto eucariotos como procariotos, que interagem em um ambiente dinâmico e em estado de equilíbrio (Carrer Filho, 2002).

As populações de microrganismos no solo coexistem em um equilíbrio ecológico que pode ser significativamente influenciado pela espécie cultivada, pelo revolvimento do solo, aplicação de insumos e por fatores climáticos predominantes, especialmente a temperatura e a umidade (Mathew et al., 2012; Jacobsen \& Hjelms $\varnothing$, 2014). A decomposição de matéria orgânica, a nitrificação, fixação do $\mathrm{N}_{2}$ atmosférico, a agregação do solo e a produção de compostos capazes de interferir no 
desenvolvimento de outros organismos são processos majoritariamente governados por microrganismos do solo (Nair \& Ngouajio, 2012).

A quantidade e diversidade de microrganismos no solo é enorme. A biomassa microbiana é responsável direta e indiretamente por processos microbiológicos e bioquímicos. Desempenham funções importantes nos ciclos biogeoquímicos e no funcionamento dos ecossistemas (BELL et al., 2005). Além dessas "funções" ambientais, os microrganismos e seus derivados possuem grande potencial biotecnológico, tais como, bioinoculantes para produção agropecuária, controle biológico, bioremediação, produção de fármacos, tais como antibióticos, enzimas, corantes entre outras substâncias químicas. Contudo a magnitude da biodiversidade microbiana ainda é pouco conhecida e consequentemente o potencial a ser explorado, visto que, conhecemos somente $1 \%$ (Moreira \& Siqueira, 2006).

Considerando-se que os microrganismos constituem excelente indicador das condições biológicas do solo, além de seu efeito sobre a produtividade agrícola, torna-se importante o conhecimento do manejo do solo e da cobertura vegetal sobre a população microbiana (Ruegger \& Tauk-Tornisielo, 2004).

Em particular, as plantas constituem um verdadeiro ecossistema microbiano. Nestas plantas hospedeiras, diferentes nichos são ocupados pelos microrganismos, tais como as superfícies das raízes e folhas (as epífitas), ou então, estas colonizando o interior de diversos tecidos das plantas. As bactérias que vivem no interior das plantas podem ser divididas em dois grupos, com base na sua relação com o hospedeiro, as associativas e as simbióticas (Souza, 2005). Entre as bactérias associadas a espécies vegetais, as bactérias fixadoras de nitrogênio são consideradas como um dos grupos de maior importância na agricultura tropical pela sua associação com as plantas leguminosas ou não.

Previati et al. (2012), trabalhando com isolamento e quantificação das populações bacterianas e de actinomicetos presentes no solo, concluiu que a contagem de microrganismos no solo, apesar de ser visto com ressalvas, ajuda a entender os processos que nele ocorrem e pode servir como indicador do impacto de diferentes atividades antrópicas. Cherubim et al. (2015), cita que a necessidade de analisar a qualidade do solo, um conjunto mínimo de indicadores englobando características físicas, químicas e biológicas são utilizados. No entanto, por ser a parte mais viva e mais ativa da matéria orgânica do solo e por atuar em importantes processos bioquímicos, estudos mostram que os indicadores biológicos são mais sensíveis que os indicadores químicos e físicos para detectar com mais antecedência alterações que ocorrem no solo em função do seu uso e manejo (Stocker et al., 2017).

A identificação e a quantificação da diversidade dos microrganismos presentes em um solo podem ser avaliado como parâmetros biológicos indicadores de estresses ecológicos e da saúde geral da flora e fauna do local (Van Bruggen \& Semenov, 2000). Desta forma, objetivou-se avaliar a população de microrganismos presente no solo em três diferentes formas de uso e manejo.

\section{Metodologia}

Trata-se de uma pesquisa quantitativa (Pereira et al., 2018). O estudo foi realizado no Instituto Federal de Ciência e Tecnologia de Roraima - Campus Novo Paraíso, no município de Caracaraí, Roraima, nas coordenadas geográficas $\mathrm{N}$ 01 ${ }^{\circ} 14^{\prime} 51,6^{\prime \prime}$ e W 60²8'20,4”, altitude de 105 m, clima do tipo tropical sazonal - Aw, na classificação de Köppen. O solo da área foi classificado como Latossolo Vermelho distrófico argissólico (Embrapa, 2013). Os tratamentos foram constituídos de três áreas com diferentes manejo e uso; área em sistema de cultivo consorciado (gliricídia, laranja e banana), área com cultivo consorciado de laranja e essência florestal (Ipê) e a área de mata. Cada área de $1600 \mathrm{~m}^{2}$ foi dividida em cinco parcelas, das quais cada uma foi subdividida em duas subparcela, nas quais foram coletadas amostras de solo na rizosfera das plantas, nas 
profundidades de $0-10$ e $10-20 \mathrm{~cm}$. As amostras foram acondicionadas em sacos plásticos estéreis e escuros, devidamente identificadas, e armazenadas em caixa térmica e posterior em câmara fria $\left(4^{\circ} \mathrm{C}\right)$.

A microbiota ativa do solo foi avaliada pela técnica de plaqueamento em superfície, em triplicata, utilizando meios de cultura específicos de crescimento para cada microrganismos. As amostras de solo foram homogeneizadas e peneiradas, em seguida retirado $10 \mathrm{~g}$ de solo de cada amostra, triturado cuidadosamente em um graal esterilizado, depois transferido para um erlenmeyer de $250 \mathrm{~mL}$ contendo $90 \mathrm{~mL}$ de solução salina $(\mathrm{NaCl}$ 0,85\%), agitadas por trinta minutos, em seguida transferido 1 $\mathrm{mL}$ desta solução para um tubo de ensaio estéril contendo $9 \mathrm{~mL}$ de solução salina ( $\mathrm{NaCl}$ 0,85\%), homogeneizada em agitador do tipo vortex, em diluição seriada decimal conforme citado por Neder, (1992). Em seguida 0,1 mL dessa diluição foi transferida para as placas de Petri em triplicata contendo meio de cultura YMA. As placas foram levadas para estufa de crescimento a $28^{\circ} \mathrm{C}$. Após 48 e 96 horas realizou-se as contagens das unidades formadoras de colônias.

A quantificação foi obtida por unidades formadoras de colônias por grama de solo (UFC g solo-1 média das contagens x diluição selecionada x 10), conforme citado por Dionísio et al. (2016). Os resultados das repetições foram empregados para cálculo de médias e erro padrão, utilizando o software Microsoft Office Excel 2010 (Microsoft).

A caracterização fenotípica foi realizada através da morfologia das colônias em meio de cultura sólido 79 (Fred \& Waskman 1928), contendo azul de bromotimol (0,5\%) e incubadas a $28{ }^{\circ} \mathrm{C}$. A caracterização foi iniciada a partir do aparecimento de no mínimo três colônias isoladas (Moreira et al. (2013). As características avaliadas foram: crescimento em dias (muito rápido - até 1 dia, rápido - 2 a 3 dias, intermediário - 4 a 5 dias, lento 6 a 10 dias, muito lento >10 dias) e alteração do pH do meio (neutro, ácido e alcalino).

As avaliações das características morfológicas dos fungos foram realizadas a partir do cultivo dos isolados em meio de cultura BDA + Estroptomicina, incubadas a $28^{\circ} \mathrm{C}$ por 8 dias (Ferreira, 2017). Foram avaliadas as características: textura da colônia (cottony, velvety, granular, powdery e creamy), forma da colônia (circular, irregular, filamentosa, rizóide, punctiforme e em fuso), elevação da colônia (plana, elevada, convexa, pulvinada, umbiculada e crateriforme), borda da colônia (inteira, ondular, lobada, irregular, filamentosa e enrolada), superfície da colônia (rugosa, verrucosa e umbiculada) e cor da colônia (creme, branca e amarela).

A quantificação do número de amonificantes foi utilizado $10 \mathrm{~g}$ de amostra do solo misturadas em solução salina e preparado a partir da diluição $10^{-1}$ sucessivamente até $10^{-5}$. Depois $1 \mathrm{~mL}$ de cada diluição foi transferida para tubo de ensaio contendo meio de cultura específico para amonificadores pela técnica de Sarathchandra (1978). Para a diluição, foram utilizados três tubos de ensaio, contendo $4 \mathrm{~mL}$ de meio de cultura e autoclavados, por 20 minutos. Posteriormente foi adicionado em cada tubo $1 \mathrm{~mL}$ das suspensões de solo; e mantidos, por 5 dias, em sala climatizada $\left(28^{\circ} \mathrm{C}\right)$. A presença de amonificadores foi determinada pela mudança de coloração (da cor laranja para rosa), que foram anotados como positivos (presença) e os sem alteração na coloração como negativo (ausência) de microrganismos amonificadores. A determinação do número mais provável (NMP) foi realizado pela contagem dos tubos que apresentaram a ocorrência de amônia, e o cálculo foi efetuado pela utilização da tabela de probabilidade de ocorrência (Sarathchandra, 1978).

A quantificação de microrganismos celulolíticos foi utilizado $10 \mathrm{~g}$ de amostra de solo diluido em solução salina ( $\mathrm{NaCl}$ 0,85\%), as diluições em série foram de $10^{-1}$ a $10^{-3}$. Foi transferido $1,0 \mathrm{~mL}$ da suspensão do solo para tubos de ensaio contendo 9,0 mL de meio líquido para organismos celulolíticos, segundo método de Bose (1963). Em cada tubo foi colocado uma tira de papel de filtro esterilizado medindo 7,0 x 1,0 cm, ficando a 2,0 cm acima do nível do meio. As culturas foram incubadas em estufa B.O.D à $28{ }^{\circ} \mathrm{C}$ por 37 dias. A estimativa do número de células viáveis foi feita por meio da utilização de tabela do número mais provável método descrito por Sarathchandra (1978). 
Para a quantificação de actinobactérias foi usado o método de semeadura em superfície, proposto por Arifuzzamanet et al. (2010). As diluições em série foram de $10^{-2}$ a $10^{-6}$, transferido $0,1 \mathrm{~mL}$ da suspensão do solo para as placas de Petri contendo meio de cultura caseína-dextrose-ágar (Clark, 1965). As culturas foram incubadas em estufa B.O.D à $28{ }^{\circ} \mathrm{C}$ por 7 dias. Após este período foram selecionadas e quantificadas as diluições que apresentaram entre 30 a 300 colônias e o resultado expresso em UFC g solo-1 (Dionísio et al., 2016).

\section{Resultados e Discussão}

Os resultados obtidos (Tabela 1), observa-se que os fatores tempo de incubação e profundidade de coleta, influenciaram no número de unidades formadoras de colônias (UFC g solo-1 ${ }^{1}$ ). As maiores contagens foram obtidas após $96 \mathrm{~h}$ de incubação e na profundidade de $0-10 \mathrm{~cm}$, independente do sistema de manejo e uso do solo.

Tabela 1- População de microrganismos (total, celulíticos, amonificadores e actinobactérias) nas áreas do estudo.

\begin{tabular}{|c|c|c|c|c|c|c|c|}
\hline \multirow{3}{*}{$\begin{array}{l}\text { Área de } \\
\text { Coleta }\end{array}$} & \multirow{3}{*}{$\begin{array}{l}\text { Profundidade } \\
\text { de coleta } \\
(\mathrm{cm})\end{array}$} & \multirow{3}{*}{$\mathrm{pH}$} & \multicolumn{2}{|c|}{ Microrganismos total } & \multirow[b]{2}{*}{ Celulíticos } & \multirow[b]{2}{*}{ Amonificadores } & \multirow[b]{2}{*}{ Actinobactérias } \\
\hline & & & $48 \mathrm{~h}$ & $96 \mathrm{~h}$ & & & \\
\hline & & & \multicolumn{5}{|c|}{. } \\
\hline Gliricídia + laranja & $0-10$ & 6.13 & $2,4 \times 10^{4}$ & $3,0 \times 10^{4}$ & $11,0 \times 10^{3}$ & $14,0 \times 10^{4}$ & $3,6 \times 10^{3}$ \\
\hline + banana & $10-20$ & 6.07 & $2,9 \times 10^{4}$ & $3,5 \times 10^{4}$ & $2,5 \times 10^{3}$ & $14,0 \times 10^{4}$ & $3,1 \times 10^{3}$ \\
\hline \multirow[t]{2}{*}{ Laranja + Ipê } & $0-10$ & 6.00 & $2,2 \times 10^{6}$ & $2,4 \times 10^{6}$ & $0,4 \times 10^{3}$ & $14,0 \times 10^{4}$ & $3,0 \times 10^{3}$ \\
\hline & $10-20$ & 6.09 & $2,1 \times 10^{6}$ & $1,7 \times 10^{6}$ & $0,35 \times 10^{3}$ & $11,0 \times 10^{4}$ & $*$ \\
\hline \multirow[t]{2}{*}{ Mata } & $0-10$ & 4.57 & $*$ & $6,8 \times 10^{5}$ & $11,0 \times 10^{3}$ & $*$ & $*$ \\
\hline & $10-20$ & 4.76 & $2,2 \times 10^{6}$ & $2,2 \times 10^{6}$ & $11,0 \times 10^{3}$ & $0,07 \times 10^{4}$ & $*$ \\
\hline
\end{tabular}

* Não houve crescimento

Análise realizada no Laboratório de Solos e Planta do IFRR, Caracaraí-RR, 2021.

Fonte: Autores.

Em relação ao pH do solo, as áreas com gliricídia, laranja e banana e laranja e ipê apresentaram pH próximo (Tabela 1). Tal fato, é em virtude do manejo de correção da acidez com calcário para o cultivo de laranja. O pH é um dos atributos físico-químicos do solo mais descritos por influenciar as diferentes comunidades microbianas que habitam os solos. Os mecanismos exatos de como esse parâmetro influencia as comunidades microbianas ainda não são bem descritos, mas sabe-se que os valores de $\mathrm{pH}$ afetam a solubilidade dos minerais no solo, afetando, portanto, a disponibilidade de nutrientes. A diversidade microbiana encontra-se diretamente relacionada com um conjunto de fatores abióticos, um deles o pH e bióticos. A interação entre esses fatores influencia diretamente a ecologia, a atividade e a dinâmica populacional de microrganismos no solo (Moreira \& Siqueira, 2006; Silva et al., 2021).

A maior quantidade de unidades formadoras de colônias (UFC g solo ${ }^{-1}$ ) apresentada no solo com plantas em consórcio com gliricídia (Gliricídia sepium (Jacq.) Steud.), é explicada por essa leguminosa, demonstra-se ser uma alternativa viável para o fornecimento de nitrogênio para as espécies frutíferas, tendo em vista sua capacidade de fixar biologicamente o nutriente (Espindola et al., 2006).

De acordo com Paula et al. (2015), as elevadas taxas de biomassa e o tempo de meia-vida curto da biomassa da gliricídia ajudam, em longo prazo, a incrementar a fertilidade do solo e a disponibilidade dos nutrientes para as culturas que estão intercaladas na área de plantio. Com isso, favoreceu o aumento da densidade populacional de microrganismos na área 
Research, Society and Development, v. 10, n. 9, e21910917966, 2021

(CC BY 4.0) | ISSN 2525-3409 | DOI: http://dx.doi.org/10.33448/rsd-v10i9.17966

com a presença de gliricídia. Para Barreto e Fernandes (2001), a gliricídia é capaz de aumentar a produtividade das culturas agrícolas as quais está associada, a partir da melhoria de característica químicas, físicas e biológicas do solo, especialmente nas camadas mais superficiais.

No solo da área de consórcio laranja e ipê apresentou uma maior quantidade de UFC $\mathrm{g}$ solo- $^{1}$ na profundidade de 0$10 \mathrm{~cm}$ (Tabela 1), corroborando com Tortora; Funke; Case, (2000), os quais afirmam que, a população é maior nos poucos centímetros da superfície do solo, e declina rapidamente com a profundidade. A atividade biológica é altamente concentrada nas primeiras camadas do solo, na profundidade entre 1 à $30 \mathrm{~cm}$. Nestas camadas, o componente biológico ocupa uma fração de menos que $0,5 \%$ do volume total do solo e representa menos que $10 \%$ da matéria orgânica. Sendo composto principalmente por microrganismos que realizam diversas funções essenciais para o funcionamento do solo. Os microrganismos decompõem a matéria orgânica, liberam nutrientes em formas disponíveis as plantas e degradam substâncias tóxicas (Kennedy \& Doran, 2002).

$\mathrm{Na}$ caracterização fenotípica dos isolados, na área com presença de gliricídia, laranja e banana, observou-se predomínio de isolados que alcalinizaram o meio de cultura (83\%) e de crescimento rápido (100\%) (Figura 1 e 2). Em relação a consistência do muco ocorreu predominância de aquosa, 15 isolados $(83,3 \%)$, seguidas por seca $(11,2 \%)$ e viscosa $(5,5 \%)$. Quanto a cor das colônias, verificou-se que 16 (88,9\%) são brancas e com diâmetro até 1 mm, 2 (11,1\%) creme.

No solo da área com laranja e ipê (sem gliricídia), observou-se a predominância de isolados que acidificaram o meio de cultura, de crescimento rápido e consistência do muco aquosa (75\%), demais $25 \%$ dos isolados desta área apresentaram reação alcalina, crescimento muito rápido (Figura 1 e 2) e consistência do muco seco. Todos os isolados desta área apresentaram borda lisa, diâmetro de $1 \mathrm{~mm}$ e cor branca. O solo dessa área, apresentou três isolados com produção de muco escassa, todas os outros apresentaram produção de muco (pouco a moderada).

$\mathrm{Na}$ área de mata, observou-se a predominância de isolados que acidificaram o meio (100\%), de crescimento muito rápido $(68,75 \%)$, rápido $(31,25 \%)$, apresentando consistência aquosa, borda lisa, diâmetro de $1 \mathrm{~mm}$ e cor branca (Figura 1 e 2). 
Research, Society and Development, v. 10, n. 9, e21910917966, 2021

(CC BY 4.0) | ISSN 2525-3409 | DOI: http://dx.doi.org/10.33448/rsd-v10i9.17966

Figura 1. Tempo de crescimento dos isolados nos diferentes manejo e uso do solo. Muito rápido até 1 dia; rápido 2-3 dias.

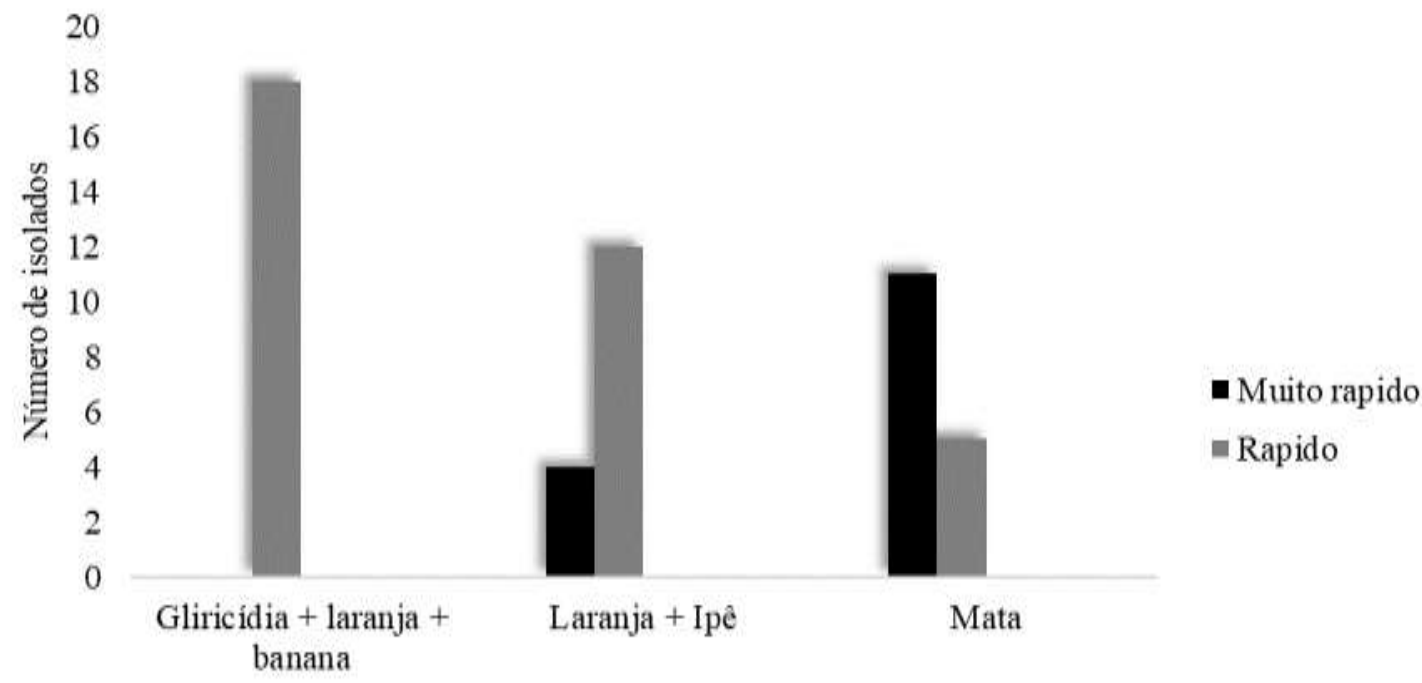

Tipo de Manejo e Uso do solo

Fonte: Autores

Algumas estirpes de rizóbios, sobretudo as de crescimento rápido, apresentam colônias com aspecto bastante gomoso, principalmente em placas com meio de cultura rico em carbono (ex.: YM). Em meios de cultura com baixo teor de carbono, as bactérias tendem a produzir colônias secas (Araújo, 1993).

Segundo Araújo (1993), as colônias são geralmente redondas, variando de achatadas a cônicas, ou até em forma de cúpula. As margens das colônias são normalmente lisas. Quando as colônias crescem sob superfície do meio elas adquirem a forma característica de lentes biconvexas. As colônias podem ser brancas opaco, ou leitosas, e até translúcidas, algumas podem produzir colônias rosadas ou amarelas. Mostrando que este trabalho apresentou características semelhantes à da literatura. O pH é um dos atributos edáficos que limita a presença de microrganismos no solo (Brockwell et al., 1991). Giongo et al., (2007), verificaram ao avaliar os fatores ambientais do solo que afetavam a diversidade de populações de Bradyrhizobium spp., isolados de nódulos de soja, que o $\mathrm{pH}$ do solo foi a principal característica que afetou a diversidade das populações, e que menor diversidade foi encontrada nos solos com $\mathrm{pH}$ mais ácido. Essa característica relaciona aos resultados obtidos neste trabalho em que os microrganismos isolados do solo da área de mata, com pH variando de 4,57 a 4,76 (Tabela 1), apresentaram reações ácida (Figura 2). 
Figura 2. Reação de alteração do pH em meio YMA contendo azul de bromotimol dos isolados nos diferentes manejo e uso do solo

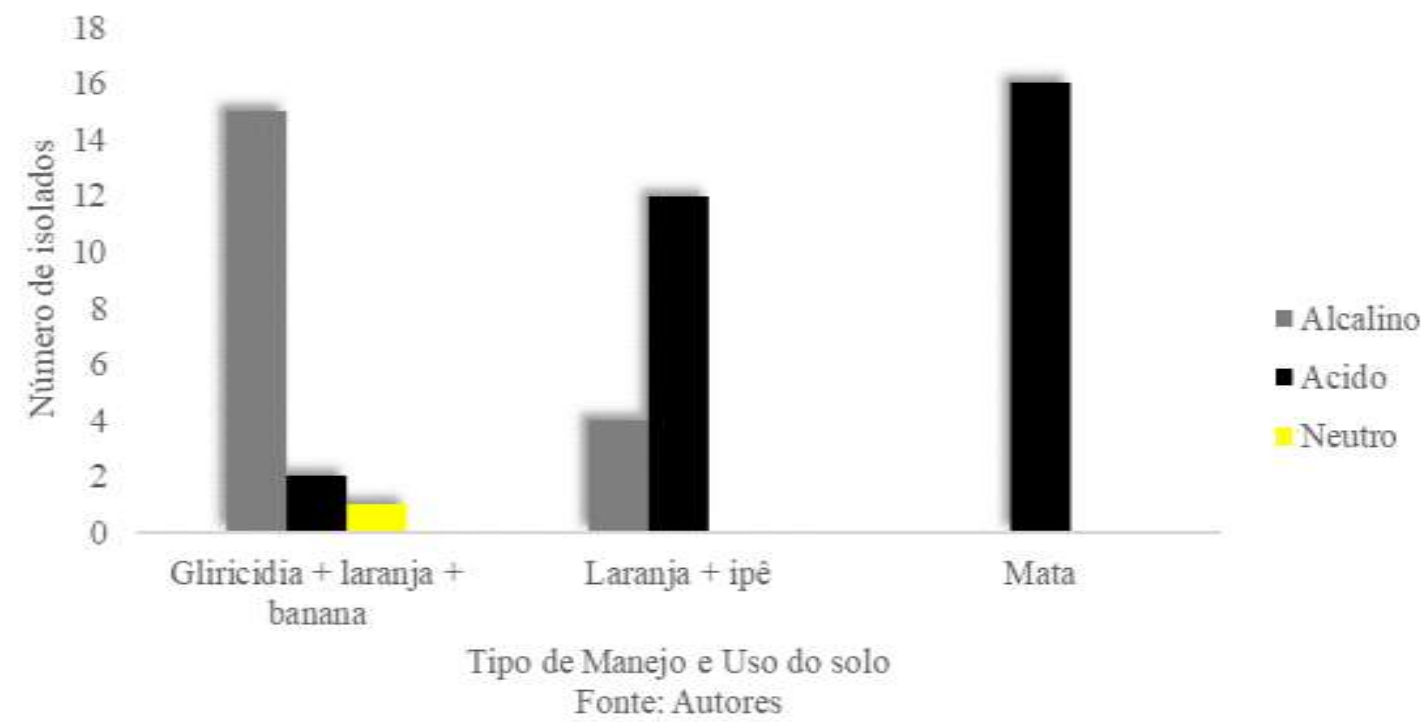

Na caracterização dos fungos isolados da área do consórcio gliricídia, laranja e banana, observou-se predominância de fungos irregulares, com colônias elevadas, bordas ondulares, superfície umbiculada; enquanto, na área do consórcio laranja e ipê, notou-se predominância de fungos irregulares, com colônias planas, bordas inteiras, superfície umbiculadas. Já na área de mata, houve predominância de fungos irregulares, com colônias elevadas, bordas ondulares, superfície umbiculada. Apenas no solo da área de mata que não apresentou bordas irregulares e superfície rugosa.

Os resultados obtidos no estudo relativos as características morfológicas assemelharam aos citados por Pelczar et al. (1980), que citam que em meios de cultura apropriados, as colônias variam quanto ao tamanho, à textura e aos bordos. Por exemplo, algumas colônias são lisas, outras enrugadas; algumas são achatadas, outras elevadas; algumas têm bordas inteiras, outras apresentam bordas irregulares ou filamentosas. As colônias jovens têm uma consistência comparável à de uma pasta espessa, a qual, após o envelhecimento, se torna mais espessa e mais seca e podem produzirem pigmentos.

A presença de microrganismos amonificadores mostrou-se semelhantes nas duas áreas manejada em sistemas de consórcio (Tabela 1). Sendo que, na área da mata apresentou um menor valor. Segundo Bandick e Dick (1999), a microbiota é favorecida pela maior diversidade florística e pela cobertura vegetal, que propicia maior acúmulo de matéria orgânica, fornecendo maior quantidade de nutrientes para o desenvolvimento da comunidade microbiana. Isso levaria a área da mata a ter um solo mais propício a esses organismos, porém não só a cobertura torna oportuno esses organismos como outros fatores que podem afetar na ausência dos mesmos. Mostrando que o solo com o consórcio de gliricídia, laranja e banana, proporcionou um ambiente favorável, já que nesta área os manejos aplicados, poda das plantas de gliricídia e pseudocaule das bananeiras, proporciona uma maior cobertura vegetal do solo, por consequência o acúmulo de matéria orgânica no mesmo.

A população celulolítica foi observada nas três áreas avaliadas (Tabela 1). Na área da mata obteve maiores valores, independente da profundidade de coleta. A área de consórcio com gliricídia, laranja e banana tiveram valor igual a área de mata na profundidade de $0-10 \mathrm{~cm}$ e a área do consórcio laranja e ipê (sem gliricídia) foi a que apresentou menor população de microrganismos celulíticos. Nos ecossistemas estáveis, como em solo sob mata, existe uma tendência de a comunidade microbiana ser maior numericamente em termos de diversidade (Cardoso, 1992). A presença de bactérias celulolíticas no solo, 
desempenham papéis semelhantes quanto a disponibilidade no solo de substrato celulose, fornecem fontes de carbono para melhorar a fertilidade do solo e manter o equilíbrio de nutrientes através da decomposição de celulose (Yang et al., 2014).

Para Ramos et al. (2012), este grupo bacteriano é fortemente influenciado pela cobertura vegetal do local, deste modo, justifica-se os resultados obtidos no trabalho, demostrando que as áreas com maior diversidade e cobertura vegetal, área do consórcio de gliricídia, laranja e banana e de mata, maior população de microrganismos no solo.

Resultados obtidos por Melonni et al. (2001), trabalhando com solo sob mata ciliar e campo de cerrado verificaram a presença de celulolíticos ser maior no solo sob mata, no entanto, não detectaram diferenças significativas entre os mesmos, corroborando com os resultados obtidos neste estudo.

O número de actinobactérias foi maior na área com gliricídia, laranja e banana, com valores semelhantes nas duas profundidades. Já na área com laranja e ipê (sem gliricídia) apenas na profundidade de $0-10$ cm apresentou número de unidades formadoras de colônias (UFC $\mathrm{g} \mathrm{solo}^{-1}$ ) com valores próximos aos da área com gliricídia, laranja e banana (Tabela 1). As actinobactérias, por sua ampla distribuição no solo, desempenham importante papel na degradação de material orgânico, também é usado como indicador da qualidade do solo (Mangamuri et al., 2014).

Segundo Arifuzzaman et al. (2010), a população de actinobactérias é afetada pela localização geográfica, temperatura e tipo de solo, $\mathrm{pH}$, teor de matéria orgânica, tipo de cultivo, aeração e umidade. $\mathrm{O}$ pH é fator determinante para a maioria das espécies, sendo ótimo entre 6,5 e 8,0 e limitante para a maioria das espécies em 5,5. Podendo ser explicado a ausência desses organismos no solo da área de mata, pois a mesma apresenta pH abaixo do desejado por essas espécies.

\section{Conclusão}

A área consorciada com gliricídia, laranja e banana apresenta um maior valor de população de microrganismos (total, celulolíticos, amonificadores e actinobactérias), mostrando ser uma planta alternativa para sistemas de consórcio agroecológico, proporcionando uma maior quantidade de microrganismo no solo, melhorando a ciclagem de nutrientes no sistema, além de ajudar no fornecimento de nitrogênio para as espécies consorciadas.

A presença da leguminosa gliricídia, associada ao manejo de podas das plantas, foi determinante para elevar a população de microrganismos no solo.

Trabalhos que envolvam o estudo de população de microrganismos do solo, em sistemas agrícolas consorciados na Amazônia devem ser desenvolvidos, para melhor utilização dos recursos disponíveis nas propriedades rurais desta região, haja vista a escassez de recursos financeiros pelos agricultores familiares. Perspectivas como outras plantas agrícolas e leguminosas nativas são parâmetros que podem ser analisados e vir a somar neste estudo.

\section{Agradecimentos}

Ao Instituto Federal de Educação, Ciência e Tecnologia de Roraima - IFRR/Campus Novo Paraíso e ao CNPq pelo apoio recebido para a realização deste trabalho E ao Núcleo de Estudo, Pesquisa, Extensão em Agroecologia (NEPEAGRO) pelo espaço disponibilizado para realização do estudo e análises.

\section{Referências}

Araújo, R. S. (1993). Mutational analysis of the cell surface and nodulation competitiveness of rhizobium legumnosarrum biovar pphaseoli. Madison: University of Wisconsin.

Arifuzzaman, M; Khatun, M. R. \& Rahman, H. (2010). Isolation and screening of actinomycetes from Sundarbans soil for antibacterial activity. African Journal of Biotechnology. 9, 4615- 9. 
Research, Society and Development, v. 10, n. 9, e21910917966, 2021

(CC BY 4.0) | ISSN 2525-3409 | DOI: http://dx.doi.org/10.33448/rsd-v10i9.17966

Bandick, A. K. \& Dick, R. P. (1999). Fild management effects on soil enzyme activities. Soil Biology and Biochemistry. 31,1471 - 9.

Barreto, A. C. \& Fernandes, M. F. (2001). Cultivo de Gliricidia sepium e Leucaena leucocephala em alamedas visando a melhoria dos solos dos tabuleiros costeiros. Pesquisa agropecuária brasileira. Brasília. 36 (10), 1287-93.

Bell, T., Newman, J. A., Silverman, B. W., Turner, S. I. \& Liley, A. K. (2005). The contribution of species richness and composition to bacterial services. Nature. 436, $1157-60$.

Brockwell, J., Pilka, A. Y. \& Holliday, R. A. (1991). Soil pH is a major determinant of the numbers of naturally ocurring Rhizobium meliloti in non-cultivated soils in central New South Wales. Australian Journal of Experimental Agriculture. 31, 211 - 9.

Cardoso, A., Potter, O. R. \& Dedecek, A. R. (1992). Estudo comparativo da degradação de solos pelo uso agrícola no Noroeste do Paraná. Pesquisa Agropecuária Brasileira. 27 (2), 349 - 53.

Cardoso, E. J. B. N. et al. (1992). Microbiologia do solo. Campinas: Sociedade Brasileira de Ciência do Solo. 360

Carrer Filho, R. (2002). Actinomicetos como agentes de biocontrole de doenças e como promotores de crescimento do tomateiro. 78 f. Dissertação (Mestrado) - Universidade Federal de Viçosa, Viçosa-MG.

Cherubin, M. R., Eitelwein, M. T., Fabbris, C., Weirich, S. W., Silva, R. F., Silva, V. R. \& Basso, C. J. (2015). Qualidade física, química e biológica de um Latossolo com diferentes manejos e fertilizantes. Revista Brasileira Ciência do Solo. 39, 615 - 25.

Clark, F. E. Agarplate method for total microbial count. In: Black, C. A., Evans, D. D., Ensminger, L. E., White, J. L. \& Clark, F. E. (1965). Methods of soil analysis. Madison: American Society of Agronomy.

Dionísio, J.A.; et al. (2016). Guia prático de biologia do solo. Curitiba:SBCS/NEPAR, 152

Espindola, J. A. A. et al. (2006). Bananeiras consorciadas com leguminosas herbáceas perenes utilizadas como coberturas vivas. Pesquisa agropecuária brasileira. Brasília. 41 (3), 415 - 20.

Ferreira, E. P. B., Stone, L. F. \& Martin-Didonet, C. C. G. (2017). População e atividade microbiana do solo em sistema agroecológico de produção. Revista Ciência Agronômica. 48 (1), 22-31.

Giongo, A., Passaglia, L. M. P., Freire, J. R. J. \& Sá, E.L.S. (2007). Genetic diversity and symbiotic efficiency of population of rhizobia of Phaseolus vulgaris L. in Brazil. Biol Fert Soils. 43, $593-8$.

Jacobsen, C.S. \& Hjelmsø, M. H. (2014). Agricultural soils, pesticides and microbial diversity, Cur. Op. Biot. 27 , 1520.

Kennedy, A. \& Doran, J. (2002). Sustainable agriculture: role of microorganisms. In: Bitton, G. (Org.) Encyclopedia of Environmental Microbiology. New York: John Wiley \& Sons. 3116 - 26.

Mangamuri, U. K., Vijayalakshmi, M. \& Poda, S. (2014). Explorration of actinobacteria from mangrove ecosystems of Nizampatnam and Coringa for antimicrobial compounds and industrial enzymes. British Biotechnology Journal. 4 (2), 173 - 82.

Mathew, R. P., Feng, Y. C., Githinji, L., Ankumah, R. \& Balkcom. K. S. (2012). Impact of no-tillage and conventional tillage systems on soil microbial communities. App. Env. S. Sc., 1-10.

Melo, V. F., Silva, D. T., Evald, A., Rocha, P. R. R. (2017). Chemical and biological quality of the soil in different systems of use in the savanna environment. RevistaAgro@mbiente on-line. 11(2): 101-10.

Melloni, R., Pereira, E. G., Trannin, I. C. B., Santos, D. R., Moreira, F. M. S. \& Siqueira, J. O. (2001). Características biológicas de solos sob mata ciliar e campo cerrado no sul de Minas Gerais. Ciência e Agrotecnologia, Lavras. 25, 7-13.

Moreira, A. \& Costa, D. G. (2014). Dinâmica da matéria orgânica na recuperação de clareiras da floresta amazônica. Pesquisa Agropecuária Brasileira, Brasília. 39(10): $1013-9$.

Moreira, F.M.S. \& Siqueira, J.O. (2006). Microbiologia e bioquímica do solo. 2.ed. Lavras, Universidade Federal de Lavras - UFLA.

Moreira, F.M.S, Cares, J.E., Zanetti, R. \& Stürmer, S. L. (2013). O Ecossistema solo: componentes, relações ecológicas e efeitos na produção vegetal. Editora UFLA - Lavras - MG, 352

Nair, A. \& Ngouajio, M. (2012). Soil microbial biomass, functional microbial diversity, and nematode community structure as affected by cover crops and compost in an organic vegetable production system. App. S. Ec., 58, 4555.

Neder, R. N. (1992). Microbiologia: manual de laboratório. Nobel.

Paula, P. D. et al. (2015). Decomposição das podas das leguminosas arbóreas gliricídia sepium e acácia angustissima em um sistema agroflorestal. Ciência Florestal. Santa Maria. 25, 791-800.

Pereira A. S., Shitsuka, D. M., Parreira, F. J., Shitsuka, R. (2018). Metodologia da pesquisa científica. UFSM.

Previati, R., Silva, J. R. R., Souza, C. R. \& Janke, L. (2012). Isolamento e quantificação das populações de bactérias em geral e de Actinomicetos presentes no solo. UNIPAR, Umuarama. 15 (2), 155 - 60. 
Research, Society and Development, v. 10, n. 9, e21910917966, 2021

(CC BY 4.0) | ISSN 2525-3409 | DOI: http://dx.doi.org/10.33448/rsd-v10i9.17966

Pelczar, M, Reid, R. \& Chan, E. C. S. (1980) Microbiologia. (1), MAKRON Books do Brasil Editora.

Ramos, M. L. G., Meneghin, M. F. S., Pedroso, C., Guimarães, C. \& Konrad, M. L. F. (2012). Efeito dos sistemas de manejo e plantio sobre a densidade de grupos funcionais de microrganismos, em solo de cerrado. Bioscience Journal. 28 (1), 58-68.

Rodrigues, H. B. Ruivo, M. L., Lôla, A. C., Mello, I. F., Moura, Q. L. \& Viana, R. S. (2010). Variabilidade quantitativa de populações microbiana observada em solo de floresta tropical úmida, associada às condições microclimáticas. Disponível em: http://www.cbmet2010.com/anais/artigos/76_91999.pdf. Acesso em: nov, 2020.

Ruegger, M. J. S. \& Tauk-Tornisielo, S. M. (2004). Atividade da celulase de fungos isolados do solo da Estação Ecológica de Juréia-Itatins, São Paulo, Brasil. Revista Brasileira de Botânica. São Paulo. 27 (2), 205-211.

Silva, T. R. G., Costa, M. L. A., Farias, L. R. A., Santos, M. A., Rocha, J. J. L. \& Silva, J. V. (2021). Fatores abióticos no crescimento e florescimento das plantas. Research, Society and Development. 10 (4), e19710413817, http://dx.doi.org/10.33448/rsd-v10i4.13817

Souza, G. M. (2005). Diversidade de bactérias endofíticas em cana-de-açúcar. Curitiba-PR.

Stöcker, C. M., Monteiro, A. B., Bamberg, A. L., Cardoso, J. H., Morselli, T. B. G. A.; Lima, A. C. R. (2017). Bioindicadores da qualidade do solo em

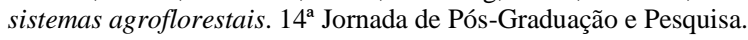

Tortora, G. J., Funke, B. R. \& Case, C. L. (2000). Microbiologia. Artmed.

Van Bruggen, A. H. C. \& Semenov, A. M. (2000). In search of biological indicators for soil health and disease suppression. App. S. Ec. 15:13-24.

Yang, J. K., Zhang, J. J., Yu, H. Y., Cheng, J.W. \& Miao, L.H. (2014). Community composition and celulase activity of cellulolytic bactéria from forest soils planted with broad-leaved deciduous and evergreen trees. Applied Microbiology and Biotechnology. 98 (3), 1149 - 458. 